\title{
TERT promoter mutations and polymorphisms as prognostic factors in primary glioblastoma
}

\author{
Mohamed Ali Mosrati ${ }^{1}$, Annika Malmström ${ }^{2}$, Malgorzata Lysiak ${ }^{1}$, Adam Krysztofiak ${ }^{1}$, \\ Martin Hallbeck ${ }^{3}$, Peter Milos ${ }^{4}$, Anna-Lotta Hallbeck ${ }^{5}$, Charlotte Bratthäll ${ }^{6}$, Michael \\ Strandéus7, Marie Stenmark-Askmalm ${ }^{8}$, Peter Söderkvist ${ }^{1}$ \\ ${ }^{1}$ Department of Clinical and Experimental Medicine, Linköping University, Linköping, Sweden \\ ${ }^{2}$ Department of Advanced Home Care and Department of Clinical and Experimental Medicine, Linköping University, Linköping, \\ Sweden \\ ${ }^{3}$ Department of Clinical Pathology and Department of Clinical and Experimental Medicine, Linköping University, Linköping, Sweden \\ ${ }^{4}$ Department of Neurosurgery and Department of Clinical and Experimental Medicine, Linköping University, Linköping, Sweden \\ ${ }^{5}$ Department of Oncology and Department of Clinical and Experimental Medicine, Linköping University, Linköping, Sweden \\ ${ }^{6}$ Department of Oncology, District Hospital, Kalmar, Sweden \\ ${ }^{7}$ Department of Oncology, Ryhov Hospital, Jönköping, Sweden \\ ${ }^{8}$ Department of Clinical Pathology and Clinical Genetics and Department of Clinical and Experimental Medicine, Linköping \\ University, Linköping, Sweden
}

Correspondence to:

Mohamed Ali Mosrati, e-mail: mohamed.ali.mosrati@liu.se

Keywords: TERT polymorphism, TERT promoter mutations, IDHI mutation, glioblastoma, IL-6

Received: March 26, $2015 \quad$ Accepted: June 12, $2015 \quad$ Published: June 22, 2015

\section{ABSTRACT}

Telomerase reverse transcriptase (TERT) activity is up-regulated in several types of tumors including glioblastoma (GBM). In the present study, 128 primary glioblastoma patients were examined for single nucleotide polymorphisms of TERT in blood and in 92 cases for TERT promoter mutations in tumors. TERT promoter mutations were observed in $86 \%$ of the tumors and of these, C228T (-124 bp upstream start codon) was detected in $75 \%$ and C250T ( $-146 \mathrm{bp}$ ) in $25 \%$ of cases. TERT promoter mutations were associated with shorter overall survival (11 vs. 20 months $p=0.002$ and 12 vs. 20, $p=0.04$ for C228T and C250T, respectively). The minor alleles of rs2736100 and rs10069690 SNP's, located in intron 2 and the promotor regions, respectively, were associated with an increased risk of developing GBM $(p=0.004$ and 0.001$)$. GBM patients having both TERT promoter mutations and being homozygous carriers of the rs2853669 C-allele displayed significantly shorter overall survival than those with the wild type allele. The rs2853669 SNP is located in a putative Ets2 binding site in the promoter (-246 bp upstream start codon) close to the C228T and C250T mutation hot spots. Interleukin-6 (IL-6) expression regulated by TERT promoter status and polymorphism, what leads us to think that TERT and IL-6 plays a significant role in GBM, where specific SNPs increase the risk of developing GBM while the rs2853669 SNP and specific mutations in the TERT promoter of the tumor lead to shorter survival.

\section{INTRODUCTION}

Gliomas are the most common malignant brain tumors, where in adults primary glioblastoma (GBM) is the most aggressive. It generally appears in the sixth through eighth decades of life [1] and the number of patients is expected to increase with an aging population. Several prognostic and/or predictive factors for overall survival (OS) have been reported such as patient age, functional status, grade of resection, type of oncological treatment, and methylation status of the $\mathrm{O}(6)$-MethylguanineDNA methyltransferase (MGMT) gene promoter [2-4]. Mutations in the isocitrate dehydrogenase 1 (IDH1) and 2 $(\mathrm{IDH} 2)$ genes, being markers for progression from lower 
grade glioma, have recently become clinical markers of predictive and prognostic importance [5]. Increased telomerase activity is one of the hallmarks of human tumors and TERT is frequently up-regulated in a variety of tumors including gliomas, preventing telomere shortening and inhibiting apoptosis and senescence $[6,7]$. Somatic mutations in the coding region of TERT are infrequent in human tumors, but germ line genetic variants and somatic mutations in the TERT promoter is frequently found in human melanomas and also other human cancers and cell lines $[8,9]$. Regulation of telomerase reactivation in tumor cells is complex and multifactorial and involves direct transcriptional activation as well as epigenetic regulation of TERT mRNA expression. Two somatic mutations, $\mathrm{C} 228 \mathrm{~T}$ and $\mathrm{C} 250 \mathrm{~T}$ located at -124 and $-146 \mathrm{pb}$ upstream from the ATG start site confer enhanced TERT promoter activity, by putatively generating consensus binding sites (GGAA) for ETS transcription factors within the TERT promoter region $[8,9]$. These mutational hot spots are most frequently found in primary glioblastomas $(82 \%)$ and oligodendrogliomas (78\%), but are less common in secondary glioblastomas $(35 \%)[10,11]$. In addition to somatic TERT promotor mutations, germ line genetic variants have been shown to predispose for breast, ovarian and bladder cancer $[12,13]$. One common polymorphism in the promoter, rs 2853669 , is located in an existing Ets2 binding sequence ( -246 bp upstream start codon), where the variant T-allele displays reduced transcriptional activity in luciferase reporter assays [13]. TERT $\mathrm{rs} 2853669$ has been shown to modulate both TERT expression and impact on prognosis in bladder cancer and GBM $[13,14]$.

McKay et al. published the first study indicating that the TERT rs2736100 polymorphism may contribute to an increased risk of lung cancer [15]. Since then, several research groups have reported associations between this SNP and cancer risk [16]. Genome wide association studies (GWAS) of glioma have shown that TERT is one of the genes that is strongly associated with glioblastoma [17-19].

To maintain telomere integrity, the protection of telomeres 1 (POT1) gene and the POT protein is regulating the substrate access for TERT, and thus responsible for limiting telomere elongation [18]. POT1 has been identified as a susceptibility locus for GBM and mutations in the POT gene have also been reported [21]. Alternative lengthening of telomeres (ALT), involving both genetic and epigenetic mechanisms, has also been suggested as an alternate way to activate telomerase [22]. In hepatocellular carcinoma (HCC) the POT1 rs7784168 SNP is significantly associated with a decreased risk of major vessel invasion and postoperative recurrence. Moreover, the POT1 rs $7784168 \mathrm{TC} / \mathrm{CC}$ genotype showed a significant effect with improved OS, and this suggests that the $\mathrm{C}$ allele of POT1 rs 7784168 may be associated with favorable prognosis for patients with HCC [23].
In addition to maintaining telomere integrity, the TERT protein presents additional functions and has been shown to interact with $\mathrm{NF \kappa B}$ and co-activate the expression of several genes, including cytokines, such as IL-6 and TNF $\alpha$, which are critical for inflammation and cancer progression [24-26].

In this study, we analyzed SNV's of the TERT and POT1 genes in blood and the relation of TERT promoter mutations in the tumors to mRNA expression of TERT and pro-inflammatory cytokines and to overall survival.

\section{RESULTS}

\section{Mutation analysis}

Somatic TERT promoter mutations were observed in $79 / 92$ primary GBMs $(85.9 \%)$. C228T was detected in 59 of these tumors $(74.7 \%)$ and C250T in $20(25.3 \%)$, the mutations being mutually exclusive. All mutations are heterozygous apart from one $\mathrm{C} 228 \mathrm{~T}$ mutation being homozygous, indicating a function as an oncogene (Figure 1).

The frequency of TERT promoter mutations in an additional cohort of 63 oligodendroglioma was $54 \%(34 / 63)$, confirming earlier observations of lower frequency in a less malignant brain tumor subtype [10]. Mutation analysis of POT1 as a potential alternative mechanism to activate telomerase, disclosed no mutations in our 92 GBM patient cohort. Five GBM patients (5.4\%) had $I D H 1 \mathrm{R} 132 \mathrm{H}$ mutations, but no mutations in $I D H 2$ (R172K) were observed. Only one GBM patient had both a C228T TERT promoter and an IDH1 mutation, revealing a significant inverse correlation ( $p<0.001$, Figure 2).

The mean age at GBM diagnosis was significantly higher in patients with a TERT promoter mutation than without, $63.2 \pm 8.64$ versus $53.15 \pm 16.4(p=0.001)$ and no difference was observed for the two different mutations.

\section{TERT polymorphisms genotyping}

Blood DNA samples were available for 128 GBM patients that were genotyped for four TERT SNPs; rs2853669 $(\mathrm{T}>\mathrm{C})$ located in the promoter region, rs2736100 (A > C), rs10069690 (C > T) and rs4246742 $(\mathrm{T}>\mathrm{A})$ located in introns 2,4 and 8 respectively. Two of these SNPs, rs2736100 and rs10069690 are in $\operatorname{LD}\left(D^{\prime}=0.83\right)$. Multivariate logistic regression analysis showed that homozygosity for the $\mathrm{C}$ variant of rs2736100 and $\mathrm{T}$ for rs 10069690 , were associated with a strong significantly increased risk of developing primary glioblastoma compared to the corresponding wild type AA and $\mathrm{CC}$ genotypes $(\mathrm{OR}=2.16,95 \% \mathrm{CI}$ $1.23-3.8, p=0.004$ and $\mathrm{OR}=3.12,95 \%$ CI $1.58-$ $6.17, p=0.001$, respectively (Table 1 ). The AC and CT genotypes displayed an intermediate but still significantly increased risk $(\mathrm{OR}=1.55,95 \%$ CI $0.92-2.16, p=$ 
A

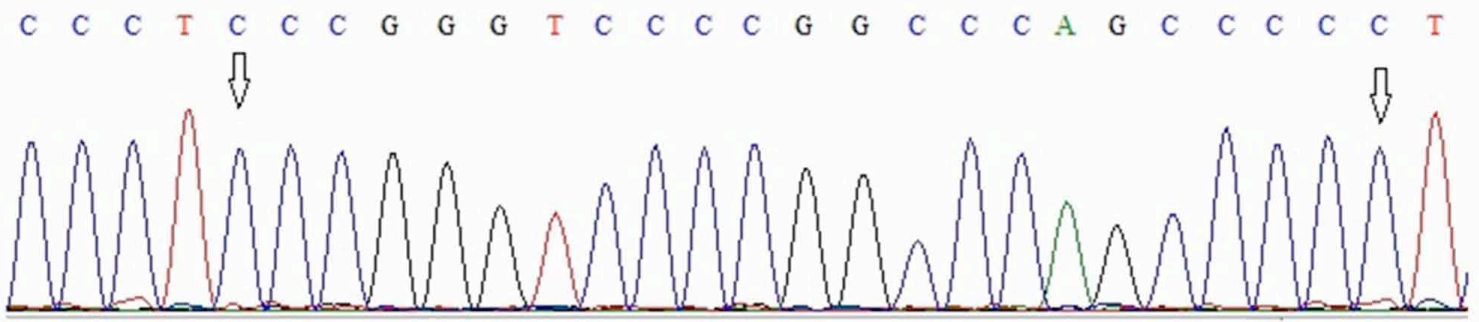

B

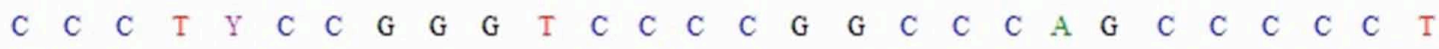
$\mathrm{C} 250 \mathrm{~T}$

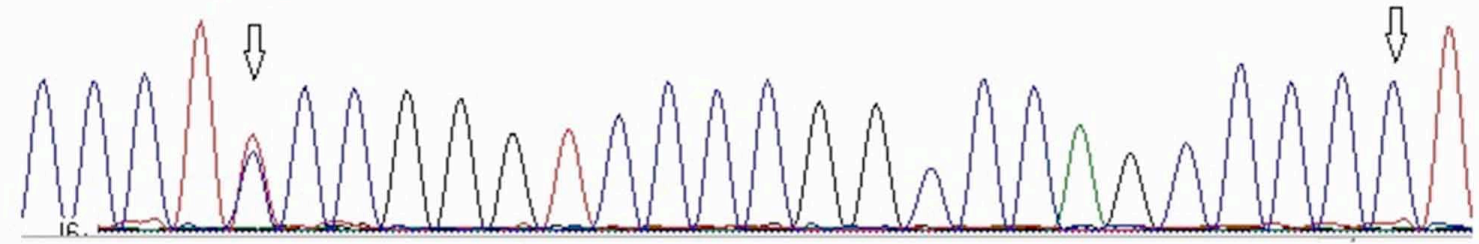

C

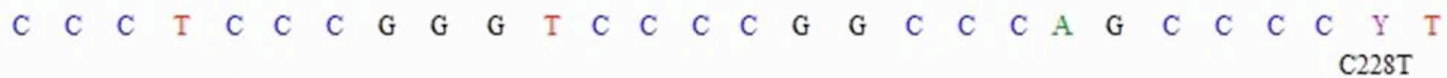

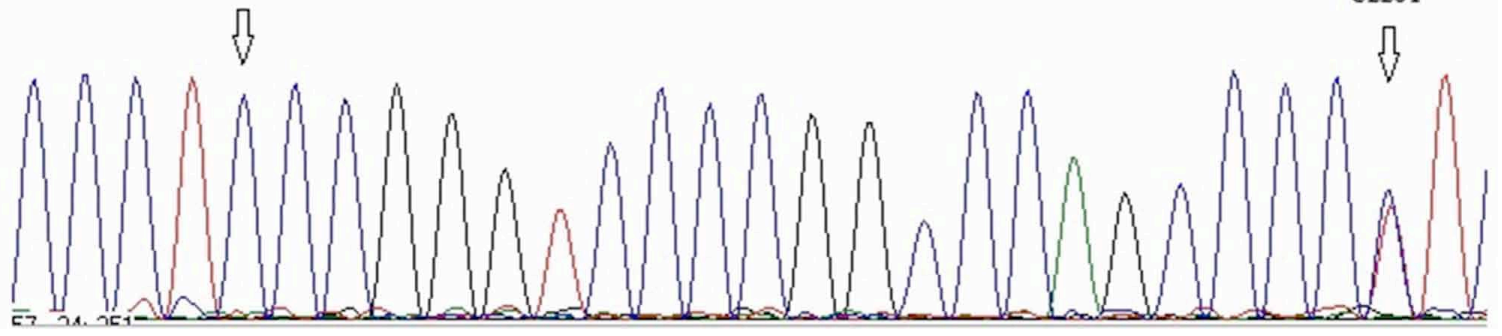

Figure 1: Electropherograms showing sequence of TERT promoter region with two hot-spot mutations C228T and C250T A. wild type C250 and C228, B. wild type C228 and C250T mutation, C. C228T mutation and wild type C250.
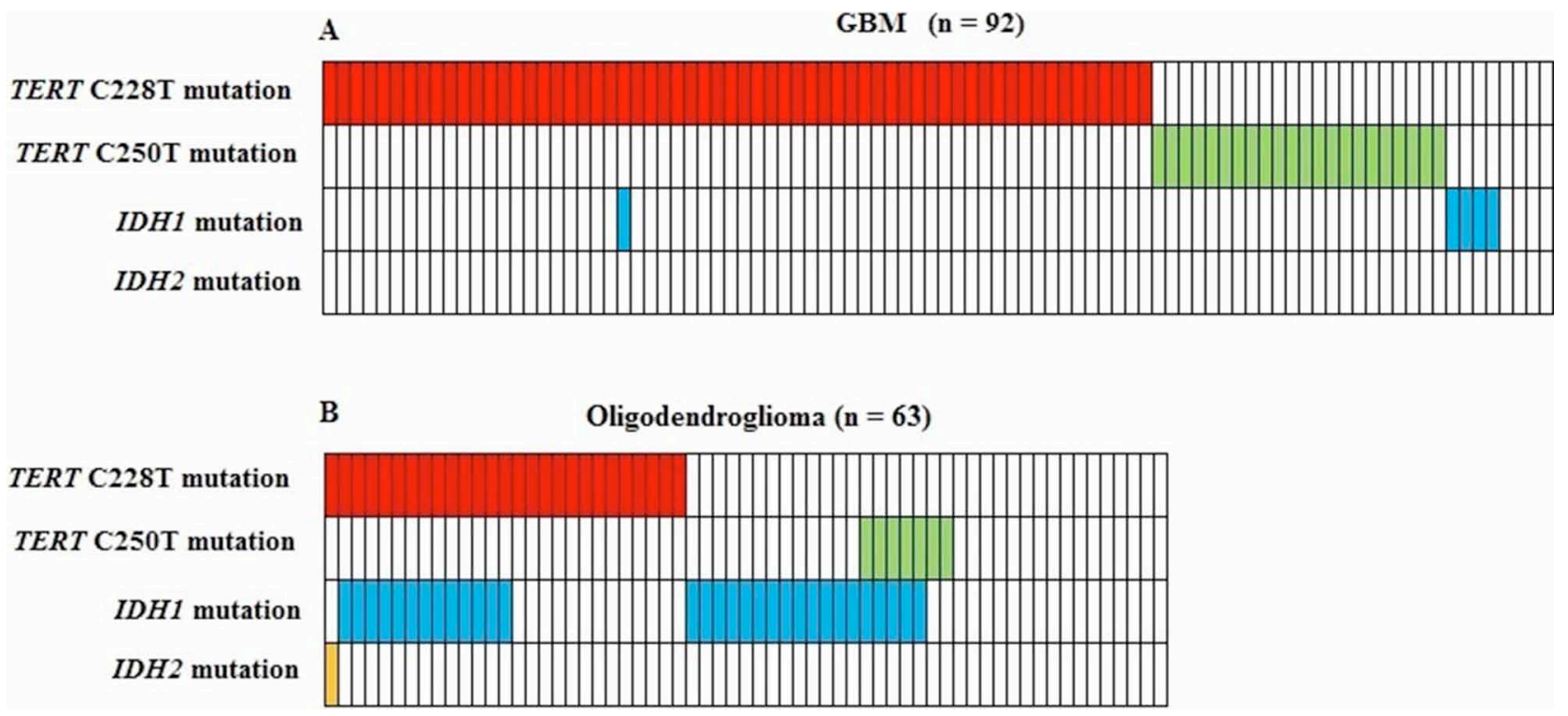

Figure 2: Correlation between TERT promoter mutations and IDH1/IDH2 mutations in 92 glioblastoma A. and 63 oligodendroglioma B. Five GBM patients had IDH1 mutations, but no mutations in IDH2 were observed. Only one GBM patient had both a C228T TERT promoter and an IDH1 mutation, revealing a significant inverse correlation $(p<0.001)$. 
Table 1: Genotype distribution of the different polymorphisms in GBM patients and normal control population and their association with GBM susceptibility

\begin{tabular}{|c|c|c|c|c|c|}
\hline Gene & Polymorphisms & GBM $n(\%)$ & Controls $n(\%)$ & OR (95\% CI) & $p$-Value \\
\hline \multirow{24}{*}{ TERT } & rs2853669 & & & & \\
\hline & TT & $69(53.90)$ & $373(47.88)$ & & \\
\hline & $\mathrm{TC}$ & $48(37.5)$ & $341(43.77)$ & $0.76(0.51-1.13)$ & 0.10 \\
\hline & $\mathrm{CC}$ & $11(8.59)$ & $65(8.34)$ & $0.91(0.45-1.82)$ & 0.47 \\
\hline & $\mathrm{TC}+\mathrm{CC}$ & 59 & 406 & $0.78(0.54-1.14)$ & 0.12 \\
\hline & Total & 128 & 779 & & \\
\hline & rs2736100 & & & & \\
\hline & $\mathrm{AA}$ & $21(16.40)$ & $201(25.5)$ & & \\
\hline & $\mathrm{AC}$ & $66(51.56)$ & $406(51.53)$ & $1.55(0.92-2.16)$ & 0.05 \\
\hline & $\mathrm{CC}$ & $41(32.03)$ & $181(22.97)$ & $2.16(1.23-3.8)$ & 0.004 \\
\hline & $\mathrm{AC}+\mathrm{CC}$ & 107 & 587 & $1.74(1.06-2.86)$ & 0.01 \\
\hline & Total & 128 & 788 & & \\
\hline & rs10069690 & & & & \\
\hline & $\mathrm{CC}$ & $47(36.72)$ & $409(53.32)$ & & \\
\hline & $\mathrm{CT}$ & $67(52.34)$ & $319(41.60)$ & $1.82(1.22-2.72)$ & 0.002 \\
\hline & $\mathrm{TT}$ & $14(10.93)$ & $39(4.68)$ & $3.12(1.58-6.17)$ & 0.001 \\
\hline & $\mathrm{CT}+\mathrm{TT}$ & 81 & 358 & $1.96(1.33-2.89)$ & 0.0003 \\
\hline & Total & 128 & 767 & & \\
\hline & rs4246742 & & & & \\
\hline & TT & $82(64.06)$ & $520(66.41)$ & & \\
\hline & TA & 43 (33.59) & $240(30.66)$ & $1.13(0.76-1.69)$ & 0.29 \\
\hline & AA & $03(2.34)$ & $23(2.93)$ & $0.82(0.24-2.80)$ & 0.52 \\
\hline & $\mathrm{TA}+\mathrm{AA}$ & 46 & 263 & $1.10(0.75-1.63)$ & 0.33 \\
\hline & Total & 128 & 783 & & \\
\hline \multirow{6}{*}{ POT1 } & rs7784168 & & & & \\
\hline & TT & $61(47.65)$ & $318(42.74)$ & & \\
\hline & $\mathrm{TC}$ & $54(42.18)$ & 349 (46.9) & $0.80(0.54-1.19)$ & 0.16 \\
\hline & $\mathrm{CC}$ & $13(10.15)$ & $77(10.34)$ & $0.88(0.46-1.68)$ & 0.41 \\
\hline & $\mathrm{TC}+\mathrm{CC}$ & 67 & 426 & $0.81(0.56-1.19)$ & 0.17 \\
\hline & Total & 128 & 744 & & \\
\hline
\end{tabular}

0.05 and $\mathrm{OR}=1.82,95 \%$ CI $1.22-2.72, p=0.002$ ) Multivariate logistic regression analysis in the set of the 63 oligodendroglioma did not reveal any association with rs 2736100 or rs 10069690 SNPs $(\mathrm{OR}=1.37,95 \%$ CI 0.64 $-2.86, p=0.27$ and $\mathrm{OR}=1.87,95 \% \mathrm{CI} 0.68-5.12, p=$ 0.17 , respectively).

TERT rs2853669 $(\mathrm{T}>\mathrm{C})$ is located at -246 upstream the ATG start codon, in close proximity to the two somatic hot spot mutations C228T and C250T. The variant allele did not show any association with susceptibility for GBM $(\mathrm{OR}=0.91,95 \% \mathrm{CI}=0.45-1.82, p=0.47)$, which is in accordance with a suppressed transcriptional activity reported for this variant (CC) compared to the wild type variant (TT). Nevertheless rs4246742 showed no association with an increased risk for GBM or effect on survival. 


\section{Overall survival of GBM patients}

The TERT promoter mutations C228T and C250T were significantly associated with shorter survival in univariate analysis (median 11 vs. 20 months $p=0.002$ and 12 vs. 20 months, $p=0.04$ for C228T and C250T, respectively) compared to wild type tumors (Figure $3 \mathrm{~A}$ ). Interestingly, the impact of the promoter mutations on OS was influenced also by the rs2853669 genotype, where the variant allele destroys an Ets2 binding site. Patients being homozygous carriers of the $\mathrm{C}$ variant of rs2853669 SNP showed a significantly reduced OS, 8.2 months compared to TC or TT, 15.7 and 24.2 months, respectively ( $p=0.007$ and 0.02 , Figure 3B). Stratification of TERT promoter mutant patients according to presence of the polymorphic rs 2853669 SNP showed a significantly shorter OS in patients harboring TERT mutations and being CC carriers, 8.2 months compared to heterozygous TC carriers, 12.3 months $(p=0.023)$ and wild type TT, 14.8 months $(p=0.02$ Figure 3C). The Prognostic impact of age at diagnosis was analyzed for the entire GBM patient cohort using 63 years as a cut-off, being the median age of the cohort. A significantly reduced OS was shown for older patients ( $>63$ years) $p=0.05$. The impact of the TERT promoter mutations status on patient survival was also analyzed in age stratified patient subgroups, and a significantly reduced OS was observed in the subgroup older than 63 years $(p=0.02$, Supplementary Figure S1), although the patient groups are small (4 patients being wild type). In contrast, rs10069690 and rs2736100, that showed a risk for GBM ( $p=0.004$ and 0.001 respectively), had no effect on survival in our GBM cohort, the same as for rs4246742.

To evaluate whether TERT promoter mutations are independent prognostic markers compared to other risk factors for survival in the $92 \mathrm{GBM}$ patients, multivariate
Cox-regression analysis was performed including the covariates age, gender, TERT promoter mutations, $I D H I$ mutation and TERT promoter mutations combined with rs2853669. The Cox-regression analysis showed that TERT promoter mutations are independent predictors for decreased survival ( $p=0.004$ and $p=0.04$ for $\mathrm{C} 228 \mathrm{~T}$ and C250T, respectively), in addition to higher age ( $p=0.01)$. The rs2853669 CC genotype was also identified as an independent predictor of short patient survival in TERT promoter mutated patients $(p=0.002$, Table 2$)$.

\section{Gene expression}

Besides telomere elongation, telomerase harbor other functions that may contribute to carcinogenesis. The TERT protein has been suggested to co-activate NFkB to stimulate gene transcription and enhance expression of e.g IL-6, TNF $\alpha$ and other pro-inflammatory cytokines. Relative mRNA expression analysis was performed on available tumor tissue from 34 patients, four being wild type and thirty four mutated in the TERT promoter. The relative mRNA expression for IL-6 was significantly increased ( $p=0.04$, Figure $4 \mathrm{C}$ ), but no significant differences in mRNA expression were apparent for TNF $\alpha$, IL- $1 \beta$ or TERT (Figure 4A, 4D, 4F). No significant differences in mRNA expression was identified in the TERT promoter mutated group compared with the wild type group ( $p=0.43$, Figure $4 \mathrm{~A}$ ), whereas TERT was significantly increased in tumors harboring C228T (4 patients) compared to C250T mutations (28 patients) ( $p=0.0003$ ). We have shown that only TERT rs 2736100 modify NFkB mediated expression of IL-6 in GBM, to be significantly increased in patients with $\mathrm{CC}$ or $\mathrm{AC}$ genotypes compared to those with AA genotype ( $p=0.001$ and 0.02 , respectively). Figure 4E. Dividing the patients according to the IL-6 median mRNA expression level
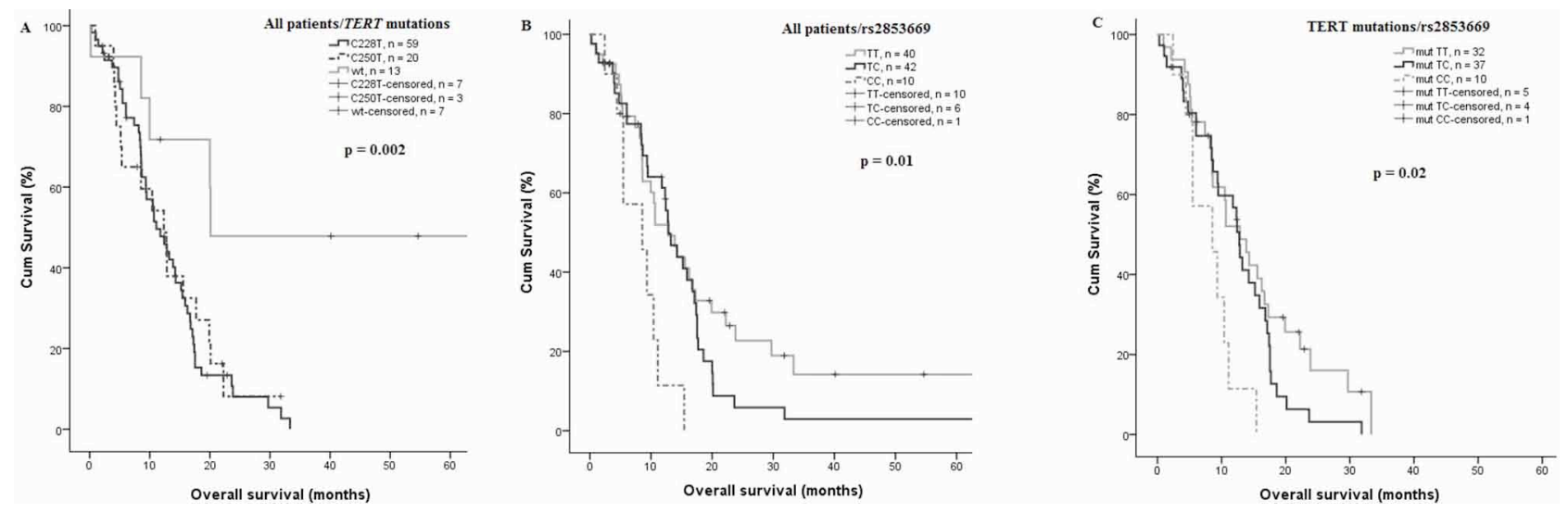

Figure 3: Effect of TERT promoter mutations on OS. A. TERT promoter mutations (C228T and C250T) was significantly associated with a shorter OS, the mean OS was 11 vs. 20 months, $p=0.002$, and 12 vs. 20 months $p=0.04$, for C228T and C250T, respectively ( $n=92$ ). B. GBM patients homozygous (CC) rs 2853669 showed a significantly shorter OS compared with heterozygous (TC) and (TT) 8.2 months vs 15.7 and 24.2 months, $p=0.007$ and 0.02 respectively $(n=92)$. C. TERT mutant patient homozygous (CC) showed a shorter OS compared to TERT mutant heterozygous and non-carriers of the C-allele, 8.2 months vs. 12.3 and 14.8, $p=0.02$ and 0.023 respectively $(n=79)$. 
Table 2: Cox regression of overall survival

\begin{tabular}{|c|c|c|c|}
\hline Covariates & HR & $95 \% \mathrm{CI}$ & $p$-Value \\
\hline Age & 1.03 & $1-1,06$ & 0.01 \\
\hline Gender ${ }^{a}$ & 0.94 & $0.61-1,58$ & 0.98 \\
\hline C228T mutation ${ }^{\mathrm{b}}$ & 4.04 & $1.55-10,51$ & 0.004 \\
\hline C250T mutation ${ }^{\mathrm{b}}$ & 3.7 & $1.3-10,51$ & 0.04 \\
\hline \multicolumn{4}{|l|}{ TERT mut+rs2853669 TT } \\
\hline TERT mut+rs2853669 TC & 4.7 & $1.92-17.16$ & 0.01 \\
\hline TERT mut+rs2853669 CC & 10.72 & $2.47-46.50$ & 0.002 \\
\hline IDH1 mut ${ }^{e}$ & 1 & $0.26-3.83$ & 0.99 \\
\hline
\end{tabular}

${ }^{\text {a) }}$ Female compared to male gender, ${ }^{\text {b) }}$ Mutated compared to non-mutated, ${ }^{c}$ Mutated + rs2853669 TC compared to Mutated rs 2853669 TT, ${ }^{d}$ Mutated+ rs 2853669 CC compared to Mutated+ rs2853669 TT, e)IDH1 mutated compared to non mutated.

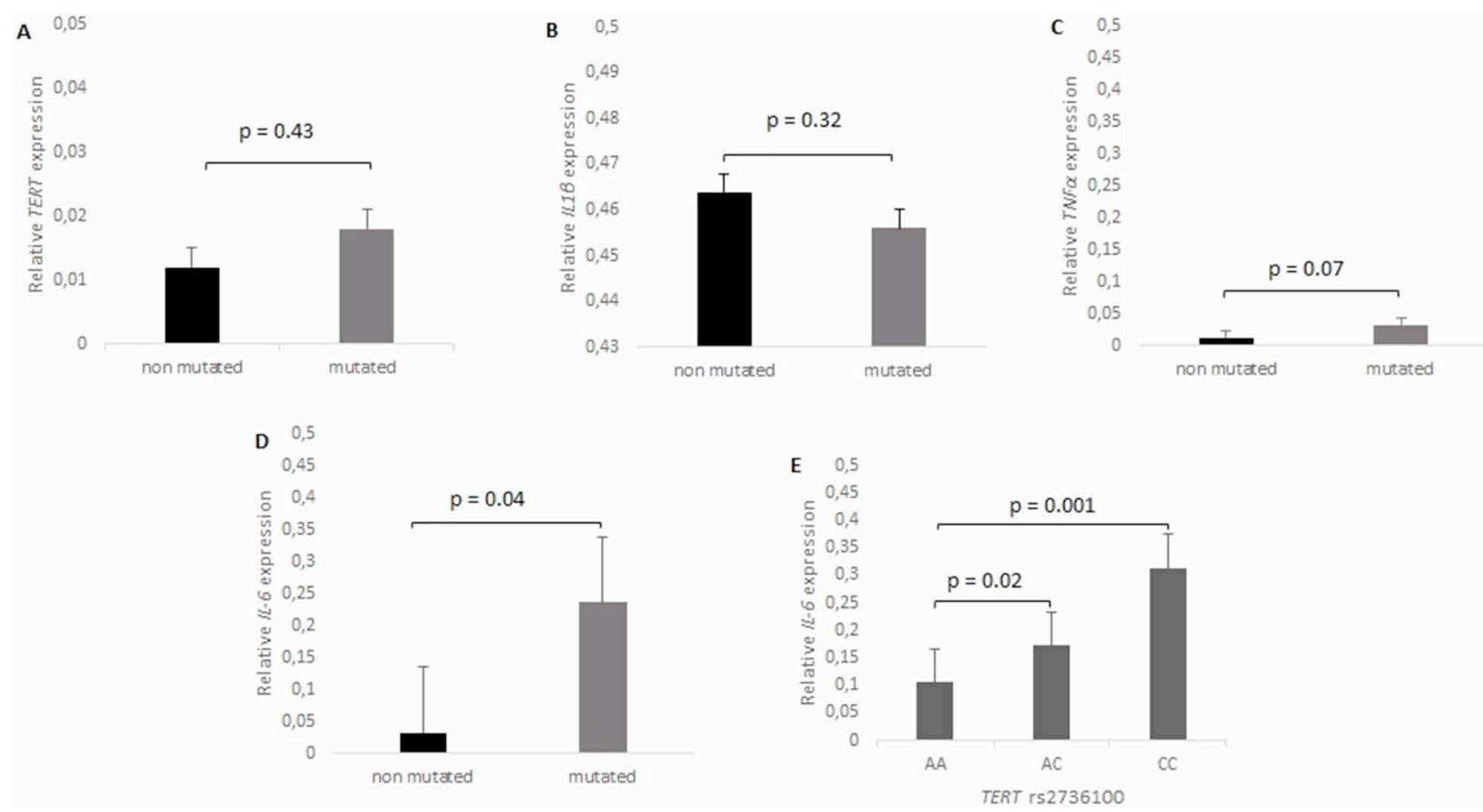

Figure 4: mRNA expression levels of TERT, IL-6, TNF $\alpha$ and IL-1 $\beta$, in relation to TERT promoter mutation status. A. TERT is $1.68(p=0.43)$ fold higher in GBM TERT mutants compared to wild type. B. No difference of IL-1 $\beta$ mRNA expression between mutated and wild type $(p=0.32)$. C. TNF $\alpha$ expression is 2.61 fold higher in TERT mutated tumors $(p=0.07)$. D. IL-6 is enhanced 7.39 fold in TERT mutated compared to wild type GBM $(p=0.04)$, and E. IL-6 was 2.95 and 1.63 fold higher in patient with CC and CA respectively compared to patient with AA rs2736100 genotype, $p=0.001$ and 0.02 respectively.

(0.081) there was no correlation between IL-6 mRNA expression levels and survival $(p=0.97), 17$ months for patients below the IL- 6 median and 16 months for those above.

\section{DISCUSSION}

Telomerase is involved in many fundamental cellular processes, such as cellular senescence and immortalization, epigenetic programming and metabolism
[27]. In this work we screened a set of 128 GBM patients regarding TERT SNVs as risk factors for developing GBM. We report a significant association of certain TERT SNPs with risk of developing glioblastoma. Four TERT SNPs were examined in white blood cells DNA. We found that TERT SNPs rs2736100 and rs10069690 located in intron 2 and 4 respectively were associated with increased risk of glioblastoma, but not for oligodendroglioma. TERT rs2736100 has previously been described in several GWAS to be associated to increased risk for glioma, [16, 28-29]. 
Our results corroborate with the findings by Simon M et al. (2010) that the frequency of rs2736100 risk genotype (CC) correlates to high-grade disease of glioma (GBM) as compared to lower grades e.g oligodendroglioma [30]. A meta-analysis including 9411 cases and 13708 controls showed that TERT rs2736100 was significantly associated to GBM also to astrocytoma and oligodendroglioma [29].

Despite their association with increased risk of GBM, Kaplan-Meier estimates showed no evidence for an independent relationship between genotype of rs2736100 or rs10069690 and OS. On the other hand, rs2853669 that is not related to a risk for developing GBM, does significantly influence OS in TERT promoter mutated GBM patients. This SNP has been shown to interfere with an Ets 2 binding site in the TERT promoter, and $\mathrm{Xu}$ and collaborators (2008) have shown that the minor genetic variant (the $\mathrm{C}$-allele) inhibits c-Myc binding to the E-box consensus site that is present with the major $\mathrm{T}$-variant allele in breast cancer cells [31]. In addition, the rs2853669 CC genotype has been shown to influence telomerase activity (TA) and telomere length maintenance in non-small cell lung cancer [32] and bladder cancer [13]. Several studies showed that the telomerase activity and TERT mRNA expression levels were significantly higher in mutated GBM as compared to those with wildtype TERT promoter $[11,14,36]$. Further, Labussière et al. (2014) have shown that GBM patients harboring the variant allele $(\mathrm{CC}+\mathrm{TC}) \mathrm{rs} 2853669$ showed a twofold reduction in TERT expression as compared with TT homozygote [33].

Survival analysis revealed that GBM patients with TERT mutations have significantly shorter OS than patients without mutations $(p=0.002)$ in accordance to other reports $[10,14,34]$. This is in contrast to Naosuke et al., who found a significant effect in primary and secondary GBMs combined $(p=0.015)$ but not in 167 primary GBMs alone $(p=0.22)$ [35]. Our results confirm the findings recently reported concerning the effect of TERT mutation and the rs2853669 C-variant on overall survival, where patients carrying both an activating TERT promoter mutation and being homozygous for the rs2853669 $\mathrm{C}$ variant have a reduced mean OS [14]. In contrast, Simon et al. found that poor survival was restricted to patients without the variant rs2853669 C-allele in GBM, [34] while in bladder cancer Rachakonda et al. (2013) have shown that the presence of the variant rs2853669 C-allele was beneficial in mutant and detrimental in a wild type TERT promoter background [13].

IDH1/IDH2 mutations are known to be diagnostic molecular markers of secondary glioblastoma [37]. Similar to other studies, GBM patients with $I D H 1$ mutations were on average 15 years younger than those without IDHI mutations $47 \pm 7.2$ versus $62.6 \pm 1.0$ years. Only one IDH1 mutant patient carried a TERT mutation. Nobusawa et al. (2009) identified 14 of 407 primary GBM (3.4\%) with $I D H 1$ mutations and these patients were on average
10 years younger. They show that GBM with IDH1 mutation diagnosed as primary had clinical and genetic profiles similar to those of secondary glioblastomas, suggesting that they may have rapidly progressed from a less malignant precursor lesion that escaped clinical diagnosis and were thus misclassified as primary [37].

In addition to TERT, POT1 is known to negatively regulate telomere length by directly inhibiting telomerase activity, or by controlling telomeric DNA substrate access to telomerase in human cells [20]. Little is known about the impact of POT1 genetic variation on telomere function and cancer risk. Ramasay and collaborators found twelve somatic mutations (5\%) in POT1 of chronic lymphoid leukemia (CLL) cases, nine detected in the N-terminal OB domain for POT1 and three mutations leading to a truncated protein. The POT1 mutations are hypothesized to favor the acquisition of malignant features in CLL [38] and may represent a possible novel approach for the clinical management of this disease. Two previous studies in breast and lung cancer in Polish and Chinese populations did not observe any association between POT1 polymorphism and disease risk [39, 40]. In our study in GBM we found no association between POT1 polymorphism and OS or risk of tumor development and no POT1 mutations were detected in our cohort.

Previous studies have shown that TERT promoter mutations result in a significant increase in TERT mRNA expression and telomerase activity in tumors compared to wild type. Nevertheless, in the tumors where RNA was available, we were unable to demonstrate a difference in our study, possibly due to a low number of wild type samples $(n=4)$ compared to 34 mutated samples. The influence of an inflammatory microenvironment has long been considered important in the initiation and progression of GBM [26]. However, the success of developing therapeutic approaches to target inflammation for GBM therapy has yet been limited [26]. Ghosh et al. (2012) have shown in gene expression analysis that leukemic cells from AML, ALL or CML patients display reduced levels of IL-6, a target gene of the transcription factor NFkB, when treated with the telomerase inhibitor MST-312. These results reiterate that inhibiting telomerase activity in cancers could be an effective means of blocking NFkB target genes that promote inflammation and malignant transformation [24]. Thus, this suggests that the TERT mutations and increased telomerase activity may maintain a tumor phenotype by stimulating an inflammatory response and angiogenesis as suggested by the increased IL-6 levels [24]. In our GBM cohort a significantly increased expression of IL- 6 but not of TNF $\alpha$ or IL-1 $\beta$ was detected according to TERT promoter mutation status. Further, IL-6 plays critical roles in the progression of nonsmall cell lung cancer (NSCLC) [25], and the increased serum concentrations in patients are associated with advanced tumor stages of several tumors (e.g., multiple myeloma, renal cell carcinoma, prostate cancer, breast 
and ovarian cancer) $[41,42]$. As TERT has been shown to modify the expression of numerous genes including IL- 6 by co-activating NFKB transcription [41, 42].Wang shows that TERT rs2736100 A/C polymorphism affect the expression of IL- 6 and IL-6 levels was significantly elevated in NSLC subjects with the CC genotype, compared to those with AA $(p<0.01)$ [25].

Our study shows similar findings, IL-6 mRNA levels were significantly increased in patients with $\mathrm{CC}$ or AC genotypes compared to those with the AA genotype ( $p=0.001$ and 0.02 , respectively. In the same context, Rolhion and collaborators found a significantly increased expression of IL-6 among 43 GBM compared to 16 non GBM brain tumors (astrocytomas, pilocytic astrocytomas, oligodendrogliomas and oligoastrocytomas) $(p<0.001)$, and suggest that IL-6 may play a central role in GBM behavior, which may serve as a suitable new potential target in the treatment of glioblastomas as well as a marker in glioma classification [43]. In our study the increased IL-6 levels are related to the TERT promoter mutation status and polymorphism. Cheng-Yi et al. demonstrated a trend to a difference on OS between patients with IL-6 positive immunohistochemistry (5/11) in GBM patients, 7 months median survival versus 16 months, $p=0.075$ [44], whereas in our cohort the median OS for patients with low IL-6 mRNA expression ( $<$ median 0.081) was 17 months in relation to those with high IL-6 expression levels $(>0.081)$, that had an median OS of 16 months $(p=0.97)$.

In conclusion, our results shows that certain TERT SNPs are associated with an increased risk of developing GBM, and an association between somatic TERT promoter mutations also results in a reduced OS. An additional negative effect is observed for simultaneous presence of TERT promoter mutations and the presence of the variant C-allele of rs2853669 SNP. Our results also indicate that the TERT rs2853669 polymorphism, TERT promoter mutations and IL-6 expression have potential to become prognostic markers of survival in GBM, which may further aid clinicians in treatment decisions.

\section{MATERIALS AND METHODS}

\section{Study subjects}

This study was approved by the Regional Ethics Committee at Linköping University, Linköping, Sweden. One hundred twenty eight patients diagnosed with primary glioblastoma were included in this study blood DNA were used for genotyping. In 92 cases, tumor tissue was available for mutation screening and in 52 of these cases both blood and tumor tissue was available. The clinical information, including age, gender and survival data, was obtained from the Swedish Cancer registry. The mean age of patients at diagnosis was $62.5 \pm 11.0$ years. The male to female ratio was 1.3:1. A control population for analyzing the role of SNPs for primary glioblastoma comprised 788 healthy individuals $(50 \%$ women, $50 \%$ men) with mean age of $54 \pm 17$ years, randomly collected from the population register from the same geographic region as the patients during the years 1998 to 2000 . For further comparison we also analyzed 63 oligodendrogliomas.

\section{DNA extraction}

Genomic DNA was extracted from blood samples and frozen tumors tissues. From blood samples DNA was extracted using Maxwell ${ }^{\circledR} 16$ Blood DNA Purification Kit according to the supplier's recommendations (Promega, Madison, WI, USA). Extraction of DNA from frozen tissue, was performed with, AllPrep DNA/RNA Mini Kit (Qiagen, USA).

\section{RNA extraction and real-time quantitative PCR}

RNA was available for sixty two GBM samples, 4 wild type and 34 containing somatic TERT promoter mutations, and was investigated for TERT mRNA expression. Total RNA from each sample was reversely transcribed into cDNA with MaximaR First Strand cDNA synthesis Kit for RT-qPCR (Fermentas, St LeonRot, Germany) according to the supplier's instructions. The relative mRNA expression of TERT, IL-6, IL- $1 \beta$ and $T N F \alpha$ was determined by real-time PCR [7900HT Fast Real-Time PCR System (Applied Biosystems)], which was performed with the TaqMan ${ }^{\circledR}$ Fast Universal PCR Master Mix (Applied Biosystems) and cDNAspecific primer/probe mixes for TERT, IL-6, IL-1 $\beta$ and $T N F \alpha$ (Hs00972656_ml, amplicon length 79 bp, Hs00985639_m1, amplicon length 66 bp, Hs01555410_ m1, amplicon length $91 \mathrm{bp}$ and Hs01113624_g1, amplicon length $143 \mathrm{bp}$, respectively) (Applied Biosystems). The relative expressions of the genes were normalized to the expression of two control genes $\beta$-glucuronidase (GUSB) (4333767F, amplicon length $81 \mathrm{bp)}$ ) and Hypoxanthineguanine phosphoribosyltransferase 1 (HPRT1) $(4333768 \mathrm{~F}$, amplicon length $100 \mathrm{bp}$ ) (Applied Biosystems) and the GBM wild type group was considered as calibrator. The PCR reactions consisted of $20 \mathrm{ng}$ cDNA, $5 \mu \mathrm{l}$ of TaqMan Fast Universal Master mix (2X), $0.5 \mu$ primer-probe assay mix in a final volume of $10 \mu \mathrm{l}$. The cycling conditions were as follows: $20 \mathrm{~s}$ in $95^{\circ} \mathrm{C}$ for denaturation and then 40 cycles consisting of $3 \mathrm{~s}$ at $95^{\circ} \mathrm{C}, 30 \mathrm{~s}$ at $60^{\circ} \mathrm{C}$. All samples were run as duplicates. Calculation of normalized gene expression was based on established methods the socalled $\Delta \Delta \mathrm{C}_{\mathrm{T}}$ method. $\Delta \mathrm{C}_{\mathrm{T}}$ was calculated from subtracting mean $\mathrm{C}_{\mathrm{T}}$ value of HPRT1 and GUSB from mean $\mathrm{C}_{\mathrm{T}}$ value of TERT. The $2^{-\triangle \mathrm{CT}}$ formula was used to calculate final relative expression of TERT, IL-6, IL-1 $\beta$ and TNF $\alpha$. 


\section{TERT SNP genotyping}

The SNPs were chosen on the basis of previous reports of their association with the risk for cancer and a comprehensive tag SNP approach. The rs2853669, rs2736100 and rs4246742 in TERT, and rs7784168 in POT1 were genotyped using TaqMan ${ }^{\circledR}$ SNP Genotyping assays (C_8773290_10, C_1844009_10, C_11772271_20, C_103023_10 respectively). Total volume per well was $10 \mu \mathrm{l}$ composed of $5 \mu \mathrm{l} \mathrm{TaqMan}{ }^{\circledR}$ Universal PCR Master Mix (2X), $0.25 \mu \mathrm{l}$ assay mix (40X), including the two allele-specific TaqMan ${ }^{\circledR}$ MGB probes, $3.75-\mu l \mathrm{H}_{2} \mathrm{O}$ and $20 \mathrm{ng}$ of DNA. All analyses were performed in ABI Prism 7500 or 7900 Sequence Detection System, using the SDS 1.3 and 2.4 software for allelic discrimination (Applied Biosystems) respectively.

The rs10069690 was genotyped in glioblastoma patients and healthy controls by pyrosequencing. A DNA fragment was amplified by PCR. Each PCR reaction consisted of $5 \mathrm{mM}$ My Taq Buffer (Bioline, UK), $1 \mathrm{U}$ My Taq DNA polymerase, $1 \mu \mathrm{M}$ of each primer (Supplementary Table S1) and $20 \mathrm{ng}$ of template DNA in a final volume of $15 \mu \mathrm{l}$. The cycling conditions were $95^{\circ} \mathrm{C}$ for $2.5 \mathrm{~min}, 35$ cycles of $95^{\circ} \mathrm{C}$ denaturation for $30 \mathrm{~s}, 66.1^{\circ} \mathrm{C}$ annealing at $30 \mathrm{~s}$ and extension at $72^{\circ} \mathrm{C}$ for $30 \mathrm{~s}$. Successful PCR was determined by $1.5 \%$ agarose gel electrophoresis. The genotypes were assessed on a PSQ96MA instrument (Qiagen, Sweden) as previously described [45]. In brief, the amplified and biotinylated PCR product was isolated with a Vacuum Prep Workstation (Qiagen, Sweden). The sequencing primer 5'-gggtgaggtggacaga-3' was annealed to the single-stranded DNA template for $2 \mathrm{~min}$ at $80^{\circ} \mathrm{C}$. The plate was then transferred to the PSQ96MA instrument and sequencing was performed with the following dNTP dispensing order: cgt agc tgc.

\section{Mutation analysis}

The TERT core promoter was amplified using MyTaq $^{\mathrm{TM}}$ DNA polymerase (Bioline, USA) and primers found in literature $[10,46]$. PCR was performed in a total volume of $15 \mu \mathrm{l}$, containing $5 \mathrm{mM}$ My Taq Buffer (comprise $5 \mathrm{mM} \mathrm{dNTP}$ and $15 \mathrm{mM} \mathrm{MgCl} \mathrm{M}_{2}$ ), $1 \mu \mathrm{M}$ of each primer (Supplementary Table S1), 1 U MyTaq ${ }^{\mathrm{TM}}$ DNA polymerase and $20 \mathrm{ng}$ of template DNA. PCR products were purified with ExoSap-IT (GE Healthcare, USA), and standard Sanger sequencing was performed according to BigDye 3.1 protocol (Applied Biosystems, USA) and capillary electrophoresis on ABI 3500 Genetic Analyzer (Applied Biosystems, USA). PCR and mutation analysis of POT1 were performed for the exons previously shown to harbor mutations (exons 5-10,18) according to the same protocol as for TERT. Primers are listed in Supplementary Table S1.

\section{$I D H 1$ and $I D H 2$ exon 4 mutations}

DNA fragments spanning exons 4 of $I D H 1$ and $I D H 2$, previously identified as hot spots for mutations in these genes, [37] were amplified by PCR. Primer sequences for PCR are listed in Supplementary Table S1. Both PCR reactions were performed according to the same protocol as for TERT promoter amplification except the annealing temperature was $55^{\circ} \mathrm{C}$.

\section{Statistical analysis}

The genotype distributions in controls was tested and found to be in Hardy-Weinberg equilibrium. The association between each SNP and risk of glioblastoma was assessed by Odds ratios (OR) with $95 \%$ confidence intervals (CI). Student's $t$-test was performed to compare mean age of the patients with and without TERT promoter mutations. Bonferroni-Holm correction was used in our statistical analysis. For survival analysis Kaplan-Meier curves were generated and tested for significance by the log-rank test. OS was the time elapsed from diagnosis of primary glioblastoma to the date of death. Multivariate Cox regression models were applied to assess the impact of TERT promoter mutations on glioblastoma patient's survival. Statistical analysis was performed with SPSS Statistics 21 (IBM Corporation, Somers, NY) and Epi info7. $P<0.05$ was considered as statistically significant. Linkage Disequilibrium (LD) between polymorphisms of the TERT gene were examined by pair-wise comparisons of D'-values using HaploView software version 4.2 (Broad institute, Boston, MA).

\section{ACKNOWLEDGMENTS}

We would also like to thank Åsa Schippert and Annette Molbaek for technical assistance.

\section{CONFLICTS OF INTEREST}

The authors declare no competing financial interests

\section{GRANT SUPPORT}

This work was supported by the Swedish Cancer foundation, Region Östergötland research fund and FORSS.

\section{REFERENCES}

1. Dolecek TA, Propp JM, Stroup NE, Kruchko C. CBTRUS statistical report: primary brain and central nervous system tumors diagnosed in the United States in 2005-2009. Neuro Oncol. 2012; 14:1-49. 
2. Lacroix M, Abid-Said D, Foumey DR, Gokaslan ZL, Shi W, DeMonte F, Lang FF, McCutcheon IE, Hassenbusch SJ, Holland E, Hess K, Michael C, Miller D, Sawaya R. A multivariate analysis of 416 patients with glioblastoma multiforme: prognosis, extent of resection, and survival. J Neurosurg. 2001; 95:190-198.

3. Laws ER, Parney IF, Huang W, Anderson F, Morris AM, Asher A, Lillehei KO, Bernstein M, Brem H, Sloan A, Berger MS, Chang S. Glioma Outcomes Investigators. Survival following surgery and prognostic factors for recently diagnosed malignant glioma: data from the Glioma Outcomes Project. J Neurosurg. 2003; 99:467-473.

4. Hegi M.E, Diserens AC, Gorlia T, Hamou MF, de Tribolet N, Weller M, Kros JM, Hainfellner JA, Mason W, Mariani L, Bromberg JE, Hau P, Mirimanoff RO, et al. MGMT gene silencing and benefit from temozolomide in glioblastoma. N Engl J Med. 2005; 352:997-1003.

5. Yan H, Parsons DW, Jin G, McLendon R, Rasheed BA, Yuan W, Kos I, Batinic-Haberle I, Jones S, Riggins GJ, Friedman H, Friedman A, Reardon D, et al. IDH1 and IDH2 mutations in gliomas. N Engl J Med. 2009; 360:765-773.

6. Hanahan D, Weinberg RA. Hallmarks of cancer: The next generation. Cell. 2011; 144:646-674.

7. Hiraga S, Ohnishi T, Izumoto S, Miyahara E, Kanemura Y, Matsumura H, Arita N. Telomerase activity and alterations in telomere length in human brain tumors. Cancer Res. 1998; 58:2117-2125.

8. Horn S, Figl A, Rachakonda PS, Fischer C, Sucker A, Gast A, Kadel S, Moll I, Nagore E, Hemminki K, Schadendorf D, Kumar R. TERT promoter mutations in familial and sporadic melanoma. Science. 2013; 339:959-961.

9. Huang FW, Hodis E, Xu MJ, Kryukov GV, Chin L, Garraway LA. Highly recurrent TERT promoter mutations in human melanoma. Science. 2013; 339:957-959.

10. Killela PJ, Reitman ZJ, Jiao Y, Bettegowda C, Agrawal N, Diaz LA Jr, Friedman AH, Friedman H, Gallia GL, Giovanella BC, Grollman AP, He TC, He Y, et al. TERT promoter mutations occur frequently in gliomas and a subset of tumors derived from cells with low rates of self-renewal. Proc Natl Acad Sci USA. 2013; 110:6021-6026.

11. Arita H, Narita Y, Fukushima S, Tateishi K, Matsushita Y, Yoshida A, Miyakita Y, Ohno M, Collins VP, Kawahara N, Shibui S, Ichimura K. Upregulating mutations in the TERT promoter commonly occur in adult malignant gliomas and are strongly associated with total $1 \mathrm{p} 19 \mathrm{q}$ loss. Acta Neuropathol. 2013; 126:267-276.

12. Bojesen SE, Pooley KA, Johnatty SE, Beesley J, Michailidou K, Tyrer JP, Edwards SL, Pickett HA, Shen HC, Smart CE, Hillman KM, Mai PL, Lawrenson K, et al. Multiple independent variants at the TERT locus are associated with telomere length and risks of breast and ovarian cancer. Nat Genet. 2013; 45:371-384.
13. Rachakonda PS, Hosen I, de Verdier PJ, Fallah M, Heidenreich B, Ryk C, Wiklund NP, Steineck G, Schadendorf D, Hemminki K, Kumar R. TERT promoter mutations in bladder cancer affect patient survival and disease recurrence through modification by a common polymorphism. PNAS. 2013; 110:17426-17431.

14. Spiegl-Kreinecker S, Lötsch D, Ghanim B, Pirker C, Mohr T, Laaber M, Weis S, Olschowski A, Webersinke G, Pichler J, Berger W. Prognostic quality of activating TERT promoter mutations in glioblastoma: interaction with the rs2853669 polymorphism and patient age at diagnosis. Neuro Oncol. 2015; 1-10.

15. McKay JD, Hung RJ, Gaborieau V, Boffetta P, Chabrier A, Byrnes G, Zaridze D, Mukeria A. Lung cancer susceptibility locus at 5p15.33. Nat Genet. 2008; 40:1404-1406.

16. Yang J, Jiao S. Increased lung cancer risk associated with the TERT rs2736100 polymorphism: an updated metaanalysis. Tumour Biol. 2014; 35:5763-5769.

17. Rajaraman P, Melin BS, Wang Z, McKean-Cowdin R, Michaud DS, Wang SS, Bondy M, Houlston R, Jenkins RB, Wrensch M, Yeager M, Ahlbom A, Albanes D, et al. Genome-wide association study of glioma and metaanalysis. Hum Genet. 2012; 131:1877-1888.

18. Egan KM, Thompson RC, Nabors LB, Olson JJ, Brat DJ, Larocca RV, Brem S, Moots PL, Madden MH, Browning JE, Ann Chen Y. Cancer susceptibility variants and the risk of adult glioma in a US case-control study. J Neurooncol. 2011; 104:535-542.

19. Jenkins RB, Wrensch MR, Johnson D, Fridley BL, Decker PA, Xiao Y, Kollmeyer TM, Rynearson AL, Fink S, Rice T, McCoy LS, Halder C, Kosel ML, et al. Distinct germ line polymorphisms underlie glioma morphologic heterogeneity. Cancer Genet. 2011; 204:13-18.

20. Kelleher C, Kurth I, Lingner J. Human protection of telomeres 1 (POT1) is a negative regulator of telomerase activity in vitro. Mol Cell Biol. 2005; 25:808-818.

21. Ferrandon S, Saultier P, Carras J, Battiston-Montagne P, Alphonse G, Beuve M, Malleval C, Honnorat J, Slatter T, Hung N, Royds J, Rodriguez-Lafrasse C, Poncet D. Telomere Profiling: Toward Glioblastoma Personalized Medecine. Mol Neurobiol. 2013; 47:64-76.

22. Nittis T, Guittat L, Stewart SA. Alternative lengthening of telomeres (ALT) and chromatin: Is there a connection? Biochimie. 2008; 90:5-12.

23. Jung SW, Park NH, Shin JW, Park BR, Kim CJ, Lee JE, Shin ES, Kim JA, Chung YH. Prognostic impact of telomere maintenance gene polymorphisms on hepatocellular carcinoma patients with chronic hepatitis B. Hepatology. 2014; 59:1912-1920.

24. Ghosh A, Saginc G, Leow SC, Khattar E, Shin EM, Yan TD, Wong M, Zhang Z, Li G, Sung WK, Zhou J, Chng WJ, Li S, et al. Telomerase directly regulates

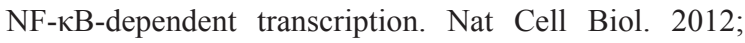
$14: 1270-1281$. 
25. Wang F, Fu P, Pang Y, Liu C, Shao Z, Zhu J, Li J, Wang T, Zhang X, Liu J. TERT rs2736100T/G polymorphism upregulates interleukin 6 expression in non-small cell lung cancer especially in adenocarcinoma. Tumour Biol. 2014; 35:4667-4672.

26. Yeung YT, McDonald KL, Grewal T, Munoz L. Interleukins in glioblastoma pathophysiology: implications for therapy. Br J Pharmacol. 2013; 168:591-606.

27. Titia de Lange: How Telomeres Solve the End-Protection Problem. Science. 2009; 326:948-952.

28. Shete S, Hosking FJ, Robertson LB, Dobbins SE, Sanson M, Malmer B, Simon M, Marie Y, Boisselier B, Delattre JY, Hoang-Xuan K, El Hallani S, Idbaih A, et al. Genome-wide association study identifies five susceptibility loci for glioma. Nat Genet. 2009; 41:899-904.

29. Zhou P, Wei L, Xia X, Shao N, Qian X, Yang Y. Association between telomerase reverse transcriptase rs2736100 polymorphism and risk of glioma. J Surg Res. 2014; 1-5.

30. Simon M, Hosking FJ, Marie Y Gousias K, Boisselier B, Carpentier C, Schramm J, Mokhtari K, Hoang-Xuan K, Idbaih A, Delattre JY, Lathrop M, Robertson LB, et al. Genetic risk profiles identify different molecular etiologies for glioma. Clin Cancer Res. 2010; 16:5252-5259.

31. Daking Xu, Dwyer J, Li H, Duan W, Liu JP. Ets2 maintains hTERT gene expression and breast cancer cell proliferation by interacting with c-Myc. J Biol Chem. 2008; 283:23567-23580.

32. Hsu CP, Hsu NY, Lee LW, Ko JL. Ets2 binding site single nucleotide polymorphism at the hTERT gene promotereffect on telomerase expression and telomere length maintenance in non-small cell lung cancer. Eur J Cancer. 2006; 42:1466-1474.

33. Labussière M, Di Stefano AL, Gleize V1, Boisselier B, Giry M, Mangesius S, Bruno A, Paterra R, Marie Y, Rahimian A, Finocchiaro G, Houlston RS, Hoang-Xuan K, Idbaih A, Delattre JY, Mokhtari K, Sanson M. TERT promoter mutations in gliomas, genetic associations and clinico-pathological correlations. Br J Cancer. 2014; 111:2024-2032.

34. Simon M, Hosen I, Gousias K, Rachakonda S, Heidenreich B, Gessi M, Schramm J, Hemminki K, Waha A, Kumar R. TERT promoter mutations: a novel independent prognostic factor in primary glioblastomas. Neuro Oncol. 2015; 17:45-52.

35. Nonoguchi N, Ohta T, Oh JE, Kim YH, Kleihues P, Ohgaki H. TERT promoter mutations in primary and secondary glioblastomas. Acta Neuropathol. 2013; 126:931-937.
36. Park CK, Lee SH, Kim JY, Kim JE, Kim TM, Lee ST, Choi SH, Park SH, Kim IH. Expression level of hTERT is regulated by somatic mutation and common single nucleotide polymorphism at promoter region in glioblastoma. Oncotarget. 2014; 305:3399-3407.

37. Nobusawa S, Watanabe T, Kleihues P, Ohgaki H. IDH1 Mutations as Molecular Signature and Predictive Factor of Secondary Glioblastomas. Clin Cancer Res. 2009; 15:6002-6007.

38. Ramsay AJ, Quesada V, Foronda M, Conde L, MartínezTrillos A, Villamor N, Rodríguez D, Kwarciak A, Garabaya C, Gallardo M, López-Guerra M, LópezGuillermo A, Puente XS, et al. POT1 mutations cause telomere dysfunction in chronic lymphocytic leukemia. Nat Genet. 2013; 45:526-530.

39. Savage SA, Chanock SJ, Lissowska J, Brinton LA, Richesson D, Peplonska B, Bardin-Mikolajczak A, Zatonski W, Szeszenia-Dabrowska N, Garcia-Closas M. Genetic variation in five genes important in telomere biology and risk for breast cancer. Br J Cancer. 2007; 97:832-836.

40. Hosgood HD, Menashe I, Shen M, Yeager M, Yuenger J, Rajaraman P, He X, Chatterjee N, Caporaso NE, Zhu Y, Chanock SJ, Zheng T, Lan Q. Pathway-based evaluation of 380 candidate genes and lung cancer susceptibility suggests the importance of the cell cycle pathway. Carcinogenesis. 2008; 29:1938-1943.

41. Culig Z. Interleukin-6 as a therapy target in oral squamous carcinoma. Expert Opin Ther Targets. 2013; 17:53-59.

42. Coward JI, Kulbe H. The role of interleukin-6 in gynaecological malignancies. Cytokine Growth Factor Rev. 2012; 23:333-342.

43. Rolhion C, Penault-Llorca F, Kémény JL, Lemaire JJ, Jullien C, Labit-Bouvier C, Finat-Duclos F, Verrelle P. Interleukin-6 overexpression as a marker of malignancy in human gliomas. J Neurosurg. 2001; 94:97-101.

44. Chang CY, Li MC, Liao SL, Huang YL, Shen CC, Pan HC. Prognostic and clinical implication of IL-6 expression in glioblastoma multiforme. J Clin Neurosci. 2005; 12:930-933.

45. Green H, Soderkvist P, Rosenberg P, Horvath G, Peterson C. mdr-1 single nucleotide polymorphisms in ovarian cancer tissue: G2677T/A correlates with response to paclitaxel chemotherapy. Clin Cancer Res. 2006; 12:854-859.

46. Liu X, Wu G, Shan Y, Hartmann C, von Deimling A, Xing M. Highly prevalent TERT promoter mutations in bladder cancer and glioblastoma. Cell Cycle. 2013; 12:1637-1638. 